\title{
Final Technical Report
}

Award Number:

Project Title:

Project Period:

Recipient Organization:

Technical Contact:

Business Contact:

DOE Project Officer:
DE-FC36-02GO12089

Industrial Assessment Center Program

10/1/2002 to $9 / 30 / 2006$

Georgia Institute of Technology

Matthew R. Soderlund, IAC Assistant Director

Georgia Institute of Technology

760 Spring St, NW, Atlanta, GA 30332

Phone: 4048943588

Fax: 4048941192

Email: matt.soderlund@innovate.gatech.edu

Serelia Woods

Georgia Institute of Technology

505 10th Street, Atlanta, GA 30332

Phone: 404-385-0866

Fax: 404-894-5945

Email: serelia.woods@osp.gatech.edu

Bill Prymak

US Department of Energy

1617 Cole Blvd., Golden, CO 80401

Phone: 303-275-4931

Fax: 303-275-4758

Email: bill.prymak@go.doe.gov

\section{$\underline{\text { Executive Summary }}$}

The Georgia Institute of Technology's Industrial Assessment Center (GT IAC) has a long history working on the IAC program with over 30 years of experience in meeting the IAC program's goals in a very effective manner since beginning participation in the IAC program's predecessor, the EADC, in 1977. During the last four year contract period, October 1, 2002 through September 31, 2006, the GT IAC continued this work with the assessments of eighty nine (89) industrial facilities. These assessments resulted in the reported implemented savings of forty eight thousand $(48,000,000) \mathrm{kWh}$ of electricity and seven hundred and fifty thousand $(750,000)$ MMBtu of natural gas. The total calculated cost savings from the recommendations implemented was five and a half million dollars $(\$ 5,500,000)$. These savings reoccur annually. However, this cost savings is the total of various recommendations that were calculated during 2002 to 2006. During this time period, energy prices were almost always lower than current 
energy prices. If you adjust the cost savings number to account for current energy prices, the cost savings would exceed nine million dollars $(\$ 9,000,000)$ reoccurring annually.

Beyond the reduction of industrial energy consumption and the cost savings benefit, education has also been an important element of this Center's work. Primarily this entailed both formal and on the job training of this Center's student employees. Over the four year time frame, this Center has had fifteen different student employees work for this Center. This Center has also instructed a graduate level senior mechanical engineering class that allowed senior engineering students to conduct IAC assessments under the supervision of IAC staff. This class exposed over one hundred students to industrial energy consumption and energy efficiency. In addition to educating students, the education of plant personnel has also been an important element for this Center.

It is believed that this Center has made effective use of IAC program resources by reducing industrial plant energy consumption and cost by helping them become more energy efficient. In turn, this has helped make domestic industry more competitive. This Center has also helped by introducing the next generation of engineers to energy efficiency in the industrial sector.

\section{$\underline{\text { Task Summary }}$}

\section{Task 1: Conduct Industrial Assessments, to include a variety of plant types and sizes and well as coverage of the geographic area defined in the Annual Workplan Industrial Assessments:}

During the four year contract period, the Georgia Institute of Technology's Industrial Assessment Center (GT IAC) has conducted IAC energy assessments at eighty nine (89) different industrial facilities. Of the plants visited, there were sixty two (62) unique types of manufacturers, i.e. different SIC codes. The most common manufacturer types visited are broken down in the following list. The SIC codes in this list account for seventeen (17) of the eighty nine (89) plants visited.

- $\quad$ SIC 2211, Broadwoven Fabric Mills, Cotton

- $\quad$ SIC 2273, Carpets and Rugs

- $\quad$ SIC 2281, Yarn Spinning Mills

- $\quad$ SIC 3089, Plastics Products, NEC

In addition to the variety of manufacture types visited, this Center also visited industrial facilities in fifty eight (58) different cities. These cities were primarily in Georgia, but were also in South Carolina, Tennessee, and Alabama.

The eighty nine (89) IAC assessments conducted during this contract term resulted in seven hundred and fifty four (754) recommendations. Two hundred and ninety five (295) of these recommendations were reported as implemented. The electricity and natural gas savings associated with these implemented recommendations was forty eight thousand $(48,000,000) \mathrm{kWh}$ and seventy hundred and fifty thousand $(750,000)$ MMBtu, respectively. The total calculated 
cost savings from the recommendations implemented was five and a half million dollars $(\$ 5,500,000)$ reoccurring annually. If these cost savings were adjusted to account for today's energy prices for Georgia, for example $\$ 0.057 / \mathrm{kWh}$ and $\$ 8 / \mathrm{MMBtu}$ for electricity and natural gas, respectively, the cost savings calculated from the implemented recommendations would exceed nine million dollars $(\$ 9,000,000)$ reoccurring annually.

\section{Task 2: Promote and increase the adoption of assessment recommendations and employ innovative methods to assist in accomplishing these goals.}

The GT IAC has worked internally to capture as much diverse talent and experience as possible to execute the requirements of the IAC program. The depth of knowledge and breath of experiences was accomplished by utilizing the Enterprise Innovation Institute's Energy and Environmental Management Center in conjunction with Mechanical Engineering Department's Energy Systems Group.

At every pre-assessment meeting this Center works with the participating companies during the time of the plant visit to identify the facility's operational goals and obstacles associated with considering new energy projects. Additionally, this Center also focuses on what current projects are ongoing or under current evaluation. It is believed that attention to such details allows for the Center to focus its efforts when evaluating assessment recommendations, and was believed will enhance the likelihood of AR implementation.

This Center continued to focus on the importance of presenting reports to the participating client companies. It was believed that the opportunity for the facility to hear a brief presentation on the report offers an ideal opportunity for this Center to expose the report to a diverse audience at the facility, increase interest in the content of the report, and answer any of the questions or concerns. This was expected to increase the likelihood of implementation. This Center conducted this type of presentation for a large portion of the companies visited. These presentations were held either in person or via teleconference.

The net result of this work on implementation of given recommendations is that two hundred and ninety five (295) of the seven hundred and fifty four (754) recommendations made were adopted. This represents an adoption rate of thirty nine percent (39\%).

\section{Task 3: Promote the IAC Program and enhance recruitment efforts for new clients and expanded geographic coverage.}

The GT IAC has made a significant effort to promote the program the IAC program both in this Center's region and nationwide. This has been done through numerous presentations to various groups and the presentation of various papers at conferences. In addition, marketing has also occurred through the delivery of marketing materials at conferences and through various industry groups. This Center also took advantage of the large reach of the Georgia Manufacturing Extension Partnership (MEP) to reach new potential IAC clients. 
This Center has reached clients in fifty eight (58) different cities during the last four years. The facilities visited were primarily in Georgia, but were also in South Carolina, Tennessee, Alabama, and North Carolina. The distribution of assessments by state was as follows.

$\begin{array}{ll}\text { Georgia } & -75 \\ \text { Tennessee } & -5 \\ \text { South Carolina } & -6 \\ \text { Alabama } & -2 \\ \text { North Carolina } & -1\end{array}$

As a result of this Center's efforts, it is believed that interest for the IAC program has remained strong in this Center's region.

\section{Task 4: Provide educational opportunities, training, and other related activities for IAC students.}

This Center has continued to hold its lunch and learn sessions monthly. These sessions offered opportunities for students and faculty staff to learn about new information in the energy field from other faculty staff that had certain areas of expertise or experience.

Prior to visiting any facility, a session was held for all new students on industrial plant safety. Students were educated on the "does and don'ts" to keep safe and look out for others safety in an industrial environment.

During the four year contract period, this Center conducted its undergraduate senior level class taught once per year in coordination with the mechanical engineering department. In this class, students learn about the energy systems and energy efficiency opportunities in industrial facilities. The lecture topics for this class included:

- Course Introduction / Industrial Energy Perspective

- Supply-side: Electricity Rates

- Supply-side: Natural Gas Rates

- Energy Use and ARs for an Example Plant

- Previsit Orientation and Plant Safety

- Lighting Conservation and AR Format

- Process support systems: Compressed Air

- Electric Motor Drives and Variable Frequency Drives

- Process support systems: Combustion \& Steam Systems

- Insulation

In these classes, students were broken into teams of four to five, and each of these teams visited an industrial plant. Under the supervision of the IAC director and other faculty staff, these student teams conducted the IAC assessment and analysis for these industrial plants, and completed the IAC report for each plant. As the class progressed, the student teams were required to make periodic presentations on the progress of their analysis. In this way, the 
students not only learned from the analysis work from the plant they visited, but also from the experiences of the other student teams. This class resulted in exposing over one hundred mechanical engineering students to the IAC program and to the process of industrial energy assessments, and for the completion of approximately twenty five assessments.

\section{Task 5: Coordinate and integrate Center activities with other Center and IAC Program} activities, DOE's Industrial Technologies programs and other EERE programs.

Personnel from the GT IAC have actively participated in DOE's Industrial Technologies programs and other EERE programs over this contract period. Some of these program activities have included:

- A DOE sponsored Plant Wide Assessment at a Shaw Plant in Aiken, SC

- Participation in the Combined Heat and Power (CHP) Regional Application Center for the southeast

- Training and qualification of four Qualified Specialist for energy systems including compressed air, steam, and process heating

- The participation in twenty eight (28) Energy Savings Assessments (ESA)

- Southeastern Partnership to Accelerate Energy Efficiency \& SEN

Task 6: Other tasks or special projects, as needed, and as determined by DOE to be advantageous to the program and in furtherance of IAC Program goals.

This Center has held numerous open enrollment workshops over the last four years. Topics for these workshops have included Strategic Energy Planning, Industrial Energy Efficiency, Natural Gas Pricing, and Georgia Electric Rates. Typically these workshops have been offered once per year, and attendance has varied from ten to twenty five attendees per workshop.

Over this contract period, this Center has worked to improve its own IAC report format and report data management. This work has allowed the completion of IAC reports to be more efficient while adding value to the reports delivered to IAC Clients.

The GT IAC personnel continue to integrate the principles of the Georgia Tech developed energy management standard MSE 2000:2005 into the IAC assessment work. It is believed that these principles are a necessity for not only achieving energy savings, but also in prioritizing energy projects and sustaining energy savings over the long term. 